
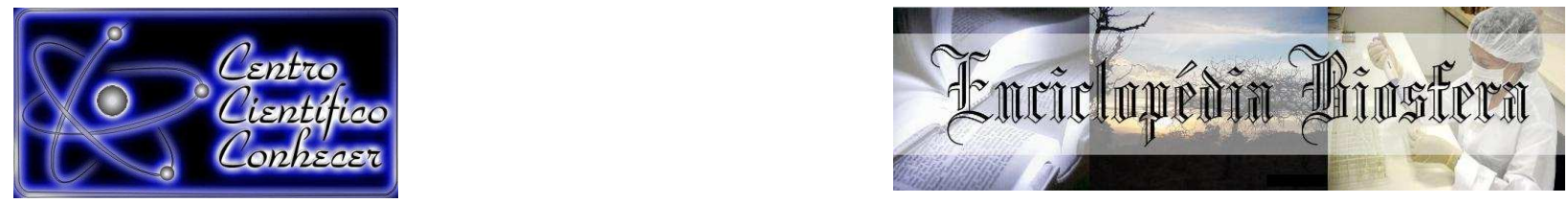

\title{
INFLUÊNCIA DE DIFERENTES SUBSTRATOS NA PRODUÇÃO DE Peltophorum
}

\section{dubium}

\section{Vinícius Jardel Szareski ${ }^{1}$, Velci Queiróz de Souza ${ }^{2}$, Maicon Nardino ${ }^{3}$, Mauricio Ferrari $^{4}$, Renan Tonin Martini ${ }^{5}$}

${ }^{1}$ Acadêmico do Curso de Agronomia - Universidade Federal de Santa Maria, campus de Frederico Westphalen - RS - Brasil (viniszareski@hotmail.com)

${ }^{2}$ Professor Doutor do Departamento de Ciências Agronômicas e Ambientais da

Universidade Federal de Santa Maria, campus de Frederico Westphalen - RS

${ }^{3}$ Doutorando em Agronomia - Universidade Federal de Pelotas - RS - Brasil

${ }^{4}$ Mestrando em Agronomia - Universidade Federal de Pelotas - RS - Brasil

${ }^{5}$ Acadêmico do Curso de Agronomia - Universidade Federal de Santa Maria, campus de Frederico Westphalen - RS - Brasil

Recebido em: 08/09/2015 - Aprovado em: 14/11/2015 - Publicado em: 01/12/2015 DOI: http://dx.doi.org/10.18677/Enciclopedia_Biosfera_2015_179

\begin{abstract}
RESUMO
A Canafístula (Pelthophorum dubium) é uma espécie nativa brasileira de alto valor comercial devido a sua utilização como planta ornamental, medicinal, na construção civil, naval e na recuperação de áreas degradadas. A espécie ocorre desde o estado da Bahia (Brasil) até a Argentina e Paraguai. Os conhecimentos sobre o tipo de substrato mais apropriado para o desenvolvimento da espécie nativa e o seu comportamento são de extrema importância para o bom estabelecimento das mesmas a campo. Neste intuito objetivou-se verificar o efeito de cinco composições de substratos no desenvolvimento de mudas de canafístula. O Experimento foi conduzido no período de abril a junho de 2014, na casa de vegetação na Universidade Federal de Santa Maria Campus de Frederico Westphalen - RS, as variáveis analisadas foram diâmetro do colo e altura de planta, avaliadas no período de três meses após o transplante. Os melhores resultados nos quesitos avaliados foram obtidos para o substrato T2; (45\% de solo argiloso, $45 \%$ de areia, $10 \%$ de vermiculita e 108 gramas de osmocote), T3: (35\% de solo argiloso, 35\% de areia, $10 \%$ de vermiculita e $20 \%$ de composto orgânico de aves) e T4: (35\% de solo argiloso, 35\% de areia, $10 \%$ de vermiculita e $20 \%$ de composto orgânico bovino).
\end{abstract}

PALAVRAS-CHAVE: Compostos orgânicos, Espécie nativa, Substratos.

\section{INFLUENCE OF DIFFERENT SUBSTRATE IN THE Peltophorum dubium PRODUCTION}

\section{ABSTRACT}

The Canafístula (Pelthophorum dubium) is a Brazilian native species of high commercial value due to its use as an ornamental, medicinal, civil, naval construction and reclamation. The species occurs from the state of Bahia to Argentina and Paraguay. Knowledge about the most appropriate type of substrate for the development of native species and their behavior are extremely important for the 
proper establishment of the same field. To this end aimed to verify the effect of five substrate compositions in developing canafístula seedlings. The experiment was conducted from April to June 2014 in a greenhouse at the Federal University of Santa Maria Campus Frederico Westphalen - RS, the variables analyzed were stem diameter and plant height, evaluated within three months after the transplantation. The best results in the variables evaluated were obtained for T2 substrate; $(45 \%$ of clay soil, $45 \%$ sand, $10 \%$ and 108 grams of vermiculite osmocote) T3: (35\% clay soil, $35 \%$ sand, $10 \%$ vermiculite and $20 \%$ organic poultry compound) and T4: (35\% clay soil, $35 \%$ sand, $10 \%$ vermiculite and $20 \%$ organic beef compound).

KEYWORDS: Organic Compounds, Native species, Substrates.

\section{INTRODUÇÃO}

A canafístula (Peltophorum dubium), pertence à família Fabaceae e divisão Angiospermae. Oriunda da América do Sul tem ciclo perene, sendo uma espécie de ampla dispersão geográfica. No Brasil encontra-se em muitos estados: Rio Grande do Sul, Santa Catarina e Paraná (CARVALHO, 2003).

A madeira desta espécie é utilizada na construção civil, marcenaria, dormentes, tornearia e carrocerias, sendo enquadrada na categoria de espécie madeireira promissora (VIVIAN et al., 2010). Geralmente, o principal destino das mudas é atender a demanda nos processos de restauração ambiental, reflorestamentos mistos de áreas degradadas (LORENZI, 2002), visto que a planta apresenta a capacidade de fixar nitrogênio atmosférico melhorando assim, a fertilidade do solo (VIVIAN et al., 2010). Além disso, a espécie é utilizada em projetos de paisagismo, arborização de parques, praças e rodovias.

Segundo ALVES et al. (2011), a ampliação de tecnologias para geração de mudas com maior qualidade e menor custo se faz necessária. Dessa forma, o tipo de substrato é um dos fatores externos mais relevantes no desenvolvimento das mudas em fase de viveiro, influenciando no crescimento e consequentemente resultando em maior grau de sobrevivência das mudas em pós semeadura (BORTOLINI et al., 2012).

A qualidade física do substrato é importante, pois é utilizado em um estádio de desenvolvimento em que a planta é pouco tolerante ao déficit hídrico. Assim, o substrato deve reunir características físicas e químicas que promovam respectivamente a retenção da umidade e a disponibilidade de nutrientes, de modo, a atender a necessidade da planta (CUNHA et al., 2006). Fatores como a estrutura, aeração, capacidade de retenção de água e grau de infestação de patógenos podem variar de um substrato para outro, interferindo no processo de desenvolvimento das mudas (MORAES et al., 2007).

Como alternativa de produção muitos viveiristas utilizam substratos constituídos principalmente de resíduos orgânicos, por apresentarem baixo custo e ampla disponibilidade no mercado (KRATZ, 2011). Deve-se tomar cuidado principalmente no que se refere à composição do substrato para que a produção e condução das mudas não sejam afetadas (FRADE JÚNIOR et al., 2011).

Em virtude da importância ambiental e econômica que esta espécie apresenta diversos trabalhos têm sido desenvolvidos, nos mais diferentes aspectos, visando melhorias no processo produtivo de mudas de espécies nativas (CRUZ et al., 2012). Diante disso, o objetivo deste trabalho foi verificar o efeito de cinco composições de substratos na produção de mudas de Peltophorum dubium. 


\section{MATERIAL E MÉTODOS}

O experimento foi conduzido no período de abril a junho de 2014, no viveiro florestal do Departamento de Engenharia Florestal da Universidade Federal de Santa Maria, campus de Frederico Westphalen. Situado nas coordenadas

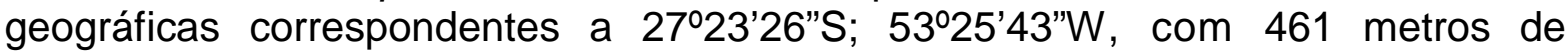
altitude.

Utilizou-se o delineamento em blocos, organizado de forma fatorial, com três épocas de avaliação e cinco substratos, dispostos em seis repetições. Cada repetição foi representada por um vaso com capacidade de três litros, onde foi transplantada uma muda. As mudas foram semeadas e cultivadas em tubetes de polipropileno com capacidade de $175 \mathrm{~cm}^{3}$, preparados com substrato comercial de fibra de palmeira moída, com a finalidade de formar mudas de mesmo padrão, eliminando assim os problemas de heterogeneidade, germinação e vigor das mesmas pelo período de 90 dias.

O experimento foi conduzido em estufa, com sombreamento artificial obtido por telas pretas de polipropileno com $50 \%$ de interceptação da luz e irrigadas por sistema de aspersão. O solo utilizado foi similar para todos os tratamentos, sendo Latossolo vermelho distrófico, contendo $60 \%$ de argila (EMBRAPA, 2006). Os tratamentos seguiram os seguintes critérios:

T1: $45 \%$ de solo argiloso peneirado, $45 \%$ de areia média e $10 \%$ vermiculita;

T2: $45 \%$ de solo argiloso, $45 \%$ de areia, $10 \%$ de vermiculita e 108 gramas de osmocote, por vaso o que corresponde a formulação 15-09-12 (fertilizante de liberação lenta de cinco a seis meses, conforme indicado pelo fabricante);

T3: $35 \%$ de solo argiloso, $35 \%$ de areia, $10 \%$ de vermiculita, $20 \%$ de composto orgânico de aves;

T4: $35 \%$ de solo argiloso, $35 \%$ de areia, $10 \%$ de vermiculita e $20 \%$ de composto orgânico bovino;

T5: $35 \%$ de solo argiloso, $35 \%$ de areia, $10 \%$ de vermiculita e $20 \%$ de composto suíno;

Os componentes dos tratamentos foram homogeneizados com o auxílio de um misturador mecânico. O transplante das mudas foi realizado no dia dois de abril do ano de 2014 , as variáveis foram aferidas em três períodos, representados por 0,30 e 60 dias após o transplantio. As variáveis analisadas foram:

- Diâmetro do colo: realizada com auxílio de paquímetro de precisão digital, na altura de dois centímetros acima do solo, resultados em milímetros.

- Altura de planta: efetuada com régua graduada e aferida do nível do solo até o ápice da planta, resultados expressos em centímetros.

Os dados obtidos foram submetidos à análise estatística, através do software "Statistical Analysis System", primeiramente efetuou-se a análise de variância a 5\% de probabilidade de erro, após realizou-se as análises complementares por meio do teste de Tukey.

\section{RESULTADOS E DISCUSSÕES}

A análise de variância revelou que houve interação entre tipos de substratos e as épocas de avaliação para as variáveis, altura de planta e diâmetro do colo. Desta forma, desmembrou-se os efeitos simples para cada tratamento de forma conjunta. 
TABELA 1 Resumo da análise de variância para o incremento na altura de planta (AP), diâmetro de colo (DC) em função dos diferentes substratos para a produção de mudas de Peltophorum dubium, em Frederico Westphalen - RS, 2015.

\begin{tabular}{|c|c|c|c|}
\hline \multirow{2}{*}{ Fator de estudo } & \multirow{2}{*}{ GL } & \multicolumn{2}{|c|}{ Quadrado médio } \\
\hline & & Diâmetro do colo & Altura de planta \\
\hline Época & 2 & $40,01^{*}$ & $198,33^{*}$ \\
\hline Substrato & 4 & $4,08^{*}$ & $115,09^{*}$ \\
\hline Época x Substrato & 8 & $1,12^{*}$ & $15,15^{\star}$ \\
\hline CV (\%) & - & 9,35 & 7,92 \\
\hline
\end{tabular}

${ }^{*}$ significativo a $5 \%$ de probabilidade de erro.

Com base nos dados inseridos na Tabela 2 e 3, observa-se que no período 1 , ou seja, na data do transplante das mudas devido a alta homogeneidade, não apresentaram diferenças significativas tanto para o diâmetro do colo quanto para altura de planta nos cinco tratamentos. Em relação aos tratamentos (Tabela 2) no período 2, o T1 apresentou menor magnitude, entretanto diferiu do tratamento três e cinco, verificou-se que o T1 no período 3 expressou inferioridade perante os demais tratamentos.

TABELA 2 Desempenho da variável diâmetro do colo em mudas de Canafístula submetidas a cinco diferentes substratos e avaliadas em três períodos após o transplante - Frederico Westphalen - RS, 2015.

\begin{tabular}{cccc}
\hline & \multicolumn{3}{c}{ Períodos de avaliação } \\
\cline { 2 - 4 } Tratamento & $\mathbf{1}$ & $\mathbf{2}$ & $\mathbf{3}$ \\
\hline T1 & $6,36 \mathrm{aB}$ & $7,29 \mathrm{bA}$ & $7,5 \mathrm{bA}$ \\
T2 & $6,51 \mathrm{aC}$ & $7,85 \mathrm{abB}$ & $9,55 \mathrm{aA}$ \\
T3 & $6,74 \mathrm{aC}$ & $8,20 \mathrm{aB}$ & $9,75 \mathrm{aA}$ \\
T4 & $6,58 \mathrm{aC}$ & $7,97 \mathrm{abB}$ & $9,11 \mathrm{aA}$ \\
T5 & $7,15 \mathrm{aB}$ & $8,43 \mathrm{aA}$ & $8,97 \mathrm{aA}$ \\
\hline CV $(\%)$ & \multicolumn{4}{c}{}
\end{tabular}

*As médias seguidas pela mesma letra minúscula na coluna e maiúscula na linha não diferem estatisticamente pelo teste de Tukey ao nível de $5 \%$ de probabilidade de erro.

Segundo SOUZA et al. (2006), a avaliação do diâmetro do colo é de fundamental importância na avaliação do potencial das mudas para sobrevivência e crescimento após o plantio da espécie. Assim, as mudas devem apresentar maior diâmetro do colo, para potencializar o equilíbrio do crescimento da parte aérea. No entanto, a definição de um valor de diâmetro do colo depende de diversos fatores como espécie, local e das técnicas de produção (GOMES, 2001). Na comparação das épocas de avaliação para a variável diâmetro do colo (Tabela 2), observa-se que os tratamentos T2, T3, T4 para o período 3, diferiram estatisticamente mostrando-se superiores aos demais períodos de avaliação. Já para os tratamentos T1 e T5 não houve diferença significativa entre o período 2 e 3 correspondente

Resultados similares foram encontrados por MUSSI et al. (2013), que trabalhando com diferentes composições de substratos orgânicos na produção de mudas de canafístula, no Departamento de Agricultura e Ambiente, do Sudeste de Minas Gerais, em 2013, verificaram que os tratamentos com dejetos também se destacaram, sendo a matéria orgânica proveniente da cama de aviário e do esterco bovino, empregada na preparação de substratos, T3 e T4, contribuíram para a 
regulação da temperatura do solo, ativando processos microbianos, melhorando a estrutura, favorecendo o desenvolvimento da planta, indiretamente aumentando o diâmetro do colo.

A estimativa do padrão de qualidade de mudas de espécies florestais nos viveiros é considerada uma das características importantes para estimar o crescimento da planta no campo. A altura de planta é muito utilizada para esta estimativa de qualidade, devido a facilidade quanto a aferição, e ainda, por não ser um método destrutivo (GOMES, 2001). Referente à altura de plantas em diferentes períodos de avaliação (Tabela 3), observou-se que aos 30 dias após transplantes, somente o T2 diferiu estatisticamente e mostrou-se superior aos demais tratamentos. Aos 60 dias não foram observadas mudanças no comportamento das mudas nos cinco tratamentos. Em relação aos tratamentos, somente os tratamentos T2 e T3 diferiram estatisticamente entre tratamentos, e expressaram superioridade aos períodos 2 e 3 .

O tratamento que obteve o melhor resultado, ao final do período de avaliação, 60 dias, foi T2, (Tabela 3) o qual empregou a utilização do osmocote no substrato. Este resultado pode ser explicado devido aos benefícios dos fertilizantes de liberação lenta, como diminuição de perdas de nutrientes por lixiviação e a mortalidade de plantas por choque de plantio. Os fertilizantes de liberação lenta induzem um sistema de liberação por osmose, e a taxa de liberação é alta em maiores temperaturas, ou seja, coincidindo com o período de crescimento mais ativo das plantas (TOMASZEWSKA et al., 2002).

Em estudos realizados por PEZZUTTI, (1999), avaliando este fertilizante de liberação lenta, na produção de mudas de ipê roxo e angico branco em casa de vegetação, cultivadas à base de substrato orgânico e fertilizante de liberação lenta, observou que as mudas apresentaram resposta positiva ao fertilizante tanto em incremento na altura como diâmetro do colmo.

Entretanto em estudo de PERONI, (2012) todos os tratamentos formulados utilizando lodo de esgoto juntamente com o composto orgânico (com proporções de $1: 1$ de esterco bovino e palha de café in natura) resultaram em melhores médias de crescimento em altura para Eucalyptus grandis. De maneira semelhante, VIEIRA et al. (2009) com o objetivo de avaliarem o crescimento de mudas de Crindiúva (Trema micrantha L. Blume) em diferentes composições de substratos orgânicos, verificaram que os substratos que continham esterco bovino foram os melhores para produção de mudas da espécie para a maioria das características testadas incluindo a altura e diâmetro do colo.

TABELA 3 Desempenho da variável altura de planta em mudas de Canafístula submetidas a cinco diferentes substratos e avaliadas em três períodos após o transplante. Frederico Westphalen - RS, 2015.

\begin{tabular}{cccc}
\hline & \multicolumn{3}{c}{ Períodos de avaliação } \\
\cline { 2 - 4 } Tratamento & 1 & 2 & 3 \\
\hline T1 & $38,28 \mathrm{aA}$ & $39,33 \mathrm{cA}$ & $39,67 \mathrm{cA}$ \\
T2 & $39,15 \mathrm{aC}$ & $45,16 \mathrm{aB}$ & $49,00 \mathrm{aA}$ \\
T3 & $39,93 \mathrm{aB}$ & $44,16 \mathrm{aA}$ & $45,67 \mathrm{aA}$ \\
T4 & $36,90 \mathrm{aA}$ & $40,33 \mathrm{bcA}$ & $41,00 \mathrm{bcA}$ \\
T5 & $37,02 \mathrm{aA}$ & $40,33 \mathrm{c} \mathrm{A}$ & $40,83 \mathrm{cA}$ \\
\hline
\end{tabular}

*As médias seguidas pela mesma letra minúscula na coluna e maiúscula na linha não diferem estatisticamente a Tukey com nível de $5 \%$ de probabilidade de erro. 


\section{CONCLUSÕES}

As maiores magnitudes em relação ao crescimento inicial das mudas de canafístula foram observadas nos tratamentos dois, três e quatro.Os compostos orgânicos cama de aviário, esterco bovino, e o fertilizante osmocote expressaram maior eficiência como fonte de nutrientes para o crescimento inicial das mudas.

\section{REFERÊNCIAS}

ALVES, E.U; ANDRADE, L. A. de; BRUNO, R. de L.A.; VIEIRA, R.M.; CARDOSO, E. de A. Emergência e crescimento inicial de plântulas de Peltophorum dubium (Spreng.) Taubert sob diferentes substratos. Revista Ciência Agronômica, v. 42, n.2, p.439-447, 2011.

BORTOLINI, M. F.; KOEHLER, H. S.; ZUFFELLATO-RIBAS, K. C.; FORTES, A. M. T. Crescimento de mudas Gleditschia amorphoides Taub. Produzidas em diferentes substratos. Ciência Florestal,v. 22, n.1, p.35-46, 2012.

CARVALHO, P. E. R. Espécies arbóreas brasileiras. Colombo: EMBRAPA Florestas, 2003, v.1. 1039 p.

CRUZ, C. A. F. E. PAIVA, H. N. de, CUNHA, A. C. M. C. M. da, Neves, J.C.L. Produção de mudas de canafístula cultivadas em Latossolo vermelho amarelo álico em resposta à macronutrientes. Cerne, v.18, n.1, p.87-98, 2012.

CUNHA, A.M. de; CUNHA, G.M. de; SARMENTO, R.A. de. et al. Efeito de 14 diferentes substratos sobre o desenvolvimento de mudas de Acacia sp. Revista Árvore, Viçosa-MG, v.3, n.2, p. 207-214, 2006.

EMPRESA BRASILEIRA DE PESQUISA AGROPECUÁRIA - EMBRAPA. Centro Nacional de Pesquisa de Solos. Sistema brasileiro de classificação de solos. 2.ed. Rio de Janeiro, 2006. 306p

FRADE JUNIOR, E. F.; ARAÚJO,J. A.; SILVA, S. B.; MOREIRA, J. G. V.; SOUZA, L. $P$. Substratos de resíduos orgânicos para produção de mudas de Ingazeiro (Inga edulis Mart) no valedo Juruá - Acre. Enciclopédia Biosfera, v.7, n.13; p.959-969, 2011.

GOMES, J. M. Parâmetros morfológicos na avaliação da qualidade de mudas de Eucalyptus grandis, produzidas em diferentes tamanhos de tubete e de dosagens de N-P-K. 2001. 126p. Tese (Doutorado em Ciência Florestal) Universidade Federal de Viçosa, Viçosa, 2001.

LORENZI, H. Árvores brasileiras. Nova Odessa: Instituto Plantarum, 2002. v. 1, $368 \mathrm{p}$.

KRATZ, D. Substratos renováveis na produção de mudas de Eucalyptus benthamii Maidenet Cambagee Mimosas cabrella Benth. 2011.121p.

MORAES, L. A. C.; GARCIA, T. B.; SOUZA, N. R.; MOREIRA, A. Indução de brotação apical em mudas provenientes de sementes e do enraizamento de estacas 
de mangostãozeiro. Acta Scientiarum Agronomy, Maringá, v. 29, n. 1, p. 665-669, 2007.

MUSSI, N. S.; CARVALHO, M. O.; SILVA, M. M.; CAMPOS, A. N. R.; CUNHA, A. C. M. VIII Congresso Brasileiro de Agroecologia, Porto Alegre. RS. 2013.

PERONI, L. Substratos renováveis na produção de mudas de Eucalyptus grandis W. Hill ex Maiden. Jerônimo Monteiro, UFES: 2012. 82 f. Dissertação (Mestrado em Ciências Florestais) - Universidade Federal do Espírito Santo, Jerônimo Monteiro, 2012.

PEZZUTTI, R.V.; HOPPE, J.M. Crescimento de mudas de eucalyptus globulus em resposta à fertilização NPK. Ciência Florestal, Santa Maria (RS), v. 9, n. 2, 1999.

SOUZA, P.A. de; VENTURIN, N.; MACEDO, R. L. G. de. Adubação mineral do ipêroxo (Tabebuia impetiginosa). Ciência Florestal, Santa Maria, v.16, n. 3, p.261-270, 2006.

TOMASZEWSKA, M.; JAROSIEWICZ, A.; KARAKULSKI, K. Physical and chemical characteristics of polymer coating in CRF formulation. Science Direct, v. 146, p. 319-323, 2002.

VIEIRA, A. R.; PEREIRA, A. J.; GONCALVES, E. O. Crescimento de mudas de Trema micrantha L. Blume em diferentes substratos orgânicos. In: VI Congresso Brasileiro de Agroecologia e II Congresso Latino americano de Agroecologia, 2009, Curitiba. Revista Brasileira de Agroecologia, 2009. v. 4. p. 597-600.

VIVIAN, M. A.; MODES, K. S.; BELTRAME, R.; SOUZA, J. T.; SANTINI, E. J.; HASELEIN, C. R. Propriedades físico-mecânicas da madeira de canafístula aos 10 anos de idade. Ciência Rural, Santa Maria, v. 40, n. 5, p. 1097- 1102, 2010. 